\title{
1991 Genel Seçimlerinde ANAP'In Seçim Kampanyasının Siyasal Kültür Ekseninde Değerlendirilmesi ve Mesut Yılmaz'ın Rolü
}

\author{
Oğuz Göksu (Arş. Gör. Dr.) \\ Gaziantep Üniversitesi İletişim Fakültesi \\ oguzgoxsu@gmail.com
}

\author{
Başvuru Tarihi: 07.05.2018 \\ Yayına Kabul Tarihi: 25.06.2018 \\ Yayınlanma Tarihi: 30.07.2018
}

\section{Öz}

Çalışma, 1991 Genel Seçimlerinde ANAP'ın siyasal iletişim uygulamalarında yer alan siyasal kültürün rolünü konu edinmiştir. Çalışma, siyasal kültür konusuna seçmen davranışları ve halkın siyasete bakış açısı anlamında değil, siyasal partilerin kültürel kodları nasıl kullandıkları bağlamında yaklaşmaktadır. Araștırmada, "Kültürel unsurlar seçim kampanyalarında verilen siyasal mesajların şekillenmesinde rol oynamaktadır" önermesinden yola çıkılarak "1991 Genel Seçimlerinde ANAP'ın seçim kampanyasında siyasal kültürden nasıl yararlanılmaktadır?" sorusuna cevap aranmaktadır. Siyasal iletişim kampanyalarını siyasal kültür göstergeleri bakımından inceleyen araştırmalarını sayısı oldukça azdır. Siyasal iletişim uygulamalarında ve seçim kampanyalarında siyasal kültürün rolünü, işlevini ve muhtevasını ortaya koymak adına bu çalışma önem arz etmektedir. Bu bağlamda 1991 Genel Seçimlerinde ANAP'ın yaptığı siyasal iletişim çalışmalarındaki; dilin, içeriğin, uygulamaların, siyasal mesajların ve seçim kampanyalarında araçsallaştırılan kültürel unsurların ortaya konulması çalışmayı farklılaştıran başlıklardır. Çalışmanın amacı, 1991 seçimlerinde Fransız reklamcı Jacques Seguela'nın ANAP için hazırladığı seçim kampanyasında siyasal kültür kodlarından nasıl yararlanıldığını belirlemektir. Ayrıca bu kampanyada hangi yerel kültür niteliklerinin yer aldığını ve siyasal liderin kültürel göstergelerden ne derecede faydalandığını tespit etmek amaçlanmaktadır. Araştırma, seçim beyannamesi, gazete ilanları, televizyon reklamları ve seçim şarkıları üzerinden yapılmıştır. Araştırma neticesinde, ANAP'ın toplum içindeki geniş kitlelere yönelik olarak vaatler ve mesajlar hazırlamasına karşın, bu mesajları gerekli kültürel kodlar ile destekleyemediği görülmüştür. ANAP'ın seçim kampanyasının bütünüyle lider odaklı olduğu ve Mesut Yılmaz’ı öne çıkaran bir siyasal kampanya tasarlandığı tespit edilmiștir.

Anahtar Sözcükler: ANAP, Siyasal İletişim, Siyasal Kültür. 
Research Article

\title{
The Evaluation of ANAP's Election Campaign in 1991 General Elections in the Context of Political Culture and the Role of Mesut Yilmaz
}

\author{
Oğuz Göksu (Asst. Prof.) \\ Gaziantep University Faculty of Communication \\ oguzgoxsu@gmail.com
}

Date Received: 07.05.2018

Date Accepted: 25.06.2018

Date Published: 30.07.2018

\begin{abstract}
This study mentioned the role of political culture in ANAP's political communication practices in the 1991 parliamentary elections. The study approaches political culture in the context of how political parties use cultural codes. The main assumption is that "Cultural elements play a role in shaping political messages given in electoral campaigns." In this context "What is the use of political culture in the election campaign of ANAP in the 1991 General Elections?" is sought. The number of studies examining political communication campaigns in terms of political culture indicators is very limited. This study is important in order to reveal the role, function and content of political culture in political communication practices and election campaigns. In this context, in ANAP's political communication studies in 1991 General Elections; language, content, practices, political messages, and cultural elements instrumentalized in electoral campaigns. The aim of the study was to find out how the political culture codes were used in the election campaign prepared by the French advertiser Jacques Seguela for the ANAP in the 1991 elections, which local cultural qualities were involved in the campaign, and how political leaders benefited from cultural indicators. The research was conducted on election declarations, newspaper advertisements, television commercials and election songs. The survey was limited to ANAP's political communication activities in the 1991 General Elections. As a result of the research, it has been seen that ANAP can not support these messages with the necessary cultural codes, despite the fact that promises and messages are prepared for large masses within the society. It has been determined that the ANAP's election campaign is totally leader-oriented and that it has designed a political campaign that highlights Mesut Yilmaz.
\end{abstract}

Keywords: ANAP, Political Communication, Political Culture. 


\section{Giriş}

1980 darbesinden sonra 1983 yılında Turgut Özal liderliğinde tek başına iktidara gelen Anavatan Partisi (ANAP), olağanüstü bir dönemin akabinde kurulduktan sonra girdiği ilk genel seçimde büyük bir başarıya imza atmıştır. Türkiye Büyük Millet Meclisi 17. dönem milletvekillerinin belirlendiği seçimlerde 1980 darbesiyle kurulan Milli Güvenlik Konseyi'nin izin verdiği yalnızca 3 parti seçime katılmış ve ANAP \%45,14 oy oranına ulaşarak 211 milletvekili çıkartmıştır. ANAP'ın seçimden birinci parti olarak çıkmasında Bülent Ecevit, Süleyman Demirel, Alparslan Türkeş ve Necmettin Erbakan'ın siyasi yasaklı olmasının payı yadsınamaz. 1987 yılında yapılan 18. dönem milletvekili genel seçimlerine iktidar partisi olarak giren ANAP, iktidar yıpranmasına uğrayarak oy oranını 9 puan düşürmesine karşın \%36,31 oy oranı ile ikinci kez tek başına iktidar olmuştur. 1989 yılının ekim ayında yapılan cumhurbaşkanlığı seçiminde Özal, seçimlerin üçüncü turunda yeterli çoğunluğa ulaşarak Celal Bayar'dan sonra Türkiye'nin ilk sivil cumhurbaşkanı olarak Kenan Evren'den koltuğu devralmış ve Türkiye Cumhuriyetinin 8. Cumhurbaşkanı olmuştur.

Özal'dan sonra diğer siyasal partilerde olduğu gibi ANAP'ta da koltuk kavgası hat safhaya ulaşmıștır. Beklentilerin aksine Özal'ın ardından sürpriz şekilde Yıldırım Akbulut başbakan olmuştur. Buna mukabil liderlik yarışı da alevlenmiş ve 90’lı yıllarda siyasal partilerdeki istikrarsızlığın ve parti içi çekişmelerin temelleri atılmıştır. 1991 yılının ortalarında ANAP'taki liderlik yarışını Mesut Yılmaz kazanmış ve böylece başbakanlık koltuğunu Yıldırım Akbulut'tan devralmıştır (Özkan, 2014, 19, 129; Tokgöz, 2010, 310).

Araștırma 20 Ekim 1991 tarihinde yapılan genel seçimler için ANAP'ın hazırladığı seçim kampanyasını konu edinmiştir. Çalışmanın amacı, siyasal kültürün ve siyasal iletişimin genel çerçevesini detaylı bir literatür taraması ile çizdikten sonra araştırma sorularına cevap olacak uygulamalı örnekler üzerinden siyasal kültürün siyasal iletişim boyutunu tartışmaktır. Araştırmada, 1991 Genel Seçimlerinde Fransız reklamcı Seguela tarafından ANAP için hazırlanan siyasal iletişim kampanyasında kullanılan siyasal kültür ögeleri tespit edilmekte ve Mesut Yllmaz'ın seçim kampanyasındaki rolü betimlenmektedir.

Çalışma, siyasal kültür konusuna seçmen davranışları ve halkın siyasete bakış açısı anlamında değil, siyasal partilerin kültürel kodları nasıl kullandıkları bağlamında yaklaşmaktadır. Siyasal iletişim kampanyalarını siyasal kültür göstergeleri bakımından inceleyen araştırmalarının sayısı oldukça azdır. Siyasal iletişim uygulamalarında ve seçim kampanyalarında siyasal kültürün rolünü, işlevini ve muhtevasını ortaya koymak adına bu çalışma önem arz etmektedir. Bu bağlamda 1991 Genel Seçimlerinde ANAP'ın yaptığı siyasal iletişim çalışmalarındaki; dilin, içeriğin, uygulamaların, siyasal mesajların ve seçim kampanyalarında araçsallaştırılan kültürel unsurların ortaya konulması çalışmayı farklılaştıran başlıklardır. Diğer yandan Türkiye'de ilk kez yabancı bir reklamcı siyasi partiyle anlaşarak seçim kampanyası gerçekleştirmiştir. Bu husus çalışmayı seçim kampanyalarını inceleyen diğer çalışmalardan ayrıştırmaktadır. Çalışmanın hedefi, dönemin iktidar partisi ANAP'ın seçim çalışmalarında en çok değindikleri konuları konjonktürel olarak o dönemin siyasal kültür kodları olarak sunmaktır.

\section{Siyasal İletişim ve Seçim Kampanyalarının Ana Hatları}

Siyaset bilimciler, siyasal sistemin işleyişi açısından, iletişim alanında çalışanlar ise; iletişimin siyaset üzerindeki rolü açısından siyasal iletişim kavramını 
irdelemektedirler (Tokgöz, 2010, 517). Siyasal iletişim olgusunun ilk örnekleri Antik Yunan'a kadar uzanmaktadır. Eski Yunan'da kitleleri yönlendirenler, polis devletleri yönetenler ve teknokratlar, bugünkü anlamıyla yaptıkları çalıșmaya 'siyasal iletişim' demeseler bile toplumları yönetirken modern anlayışta siyasal iletişimin yöntemlerinden ve tekniklerinden yararlanmışlardır (Aziz, 2007, 1). Siyasal iletişim geniş bir bakış açısıyla yazılı ve elektronik medya yoluyla iletilen büyük ölçüde aracılarla gerçekleștirilen bir iletișimdir. Siyasal iletişim genel bir kural olarak yalnızca belirlenen mesajdan ve iletiden ibaret değildir, tarihi bağlam ve siyasal atmosfer de siyasal iletişimi etkilemektedir (McNair, 2003: 29, 31). Siyasal iletişimin politik süreç bağlamında üç temel fonksiyonu yerine getirdiği kabul edilmektedir. Bunlar (Wolton, 1990, 21 den aktaran Oktay, 2002, 24):

1. Ortaya çıkan siyasal sorunların bir temele oturtulması ve tanımlanması sağlar.

2. Genel geçer bir sorunun siyasal tartışma ve uzlaşma ortamına girmesinde meşruiyet sağlar.

3. Zaman içerisinde üzerinde çokça konuşulan ve artık ortak akılda buluşulan konuların gündemden düşmesini sağlar.

Siyasal iletişim disiplinler arası bir çalışma alanı olarak pek çok konu ile bağıntılıdır. Siyasal iletişim stratejisi ve seçim kampanyaları, pazarlama, reklam, propaganda ve etik konularıyla doğrudan ilişki içerisindedir. Siyasal iletişim çalışmaları bir süreç içerisinde stratejik biçimde gerçekleşmekte, bu sürecin değişik aşamalarında seçmene ulaşmak, seçmenden oy istemek ve seçmenin sadakatini kazanmak amacı ile siyasal pazarlama, siyasal reklamcılık ve siyasal propagandadan yararlanılmakta, bunun yanı sıra tüm bu süreç kapsamında siyaset felsefesine bağlı kalarak siyasal etik değerler göz önünde bulundurulmaktadır.

Siyasal iletişim kapsamında siyasal reklamlar da geçmişte olduğu gibi bugün de belirleyici bir pozisyona sahiptir. Siyasal reklamların siyasal iletişim kampanya sürecindeki bilgi verme gücü hem kaynağından hem de içeriğinden ileri gelir. Siyasal reklamların ortaya çıkıș sürecinde hem siyasal partiler hem adaylar hem de reklam ajansları yer aldığı için iletilecek mesajın içeriği her aşamada denetlenebilir (Uztuğ, 2007, 316).

Bir seçim kampanyası planlanırken, siyasal partilerin, aday adaylarının, adayların ya da liderlerin amaçları şöyle ifade edilebilir (Topuz, 1991, 8);

1. Çoğunluğun oylarını toplayarak seçilmek

2. Seçimi kazanamasa dahi yüksek oy oranına ulaşarak gücünü belirtmek

3. Diğer partiler ya da liderler ile pazarlık edebilecek konuma gelmek

4. Seçilme şansı neredeyse hiç olmamasına karşın kendi propagandasını yaparak gelecek seçimlere yatırım yapmak.

Siyasal iletişim türleri ve yöntemleri farklı şekillerde birbirlerinin alt başlıkları olarak konumlandırılmaktadır. Siyasal iletişimi türlere ayırmak gerekirse yüz yüze iletişim ve uzaktan iletişim olarak tasnif etmek olasıdır. Yüz yüze iletişimin temel amacı seçmenler ile birincil ilişkiler geliştirmek ve vatandaşlar ile samimi, güvenilir bir diyalog ortamı kurarak bireylerin siyasal partiye olan bağlılıklarını arttırmaktır (Anık, 2000, 253).

Seçim kampanyalarının en hayati noktası siyasal iletişim sürecinde kampanyanın temel stratejilerinin belirlenmesidir. Seçim kampanyalarında uygulanacak stratejinin 
temasıve seçmene iletilecek mesajın belirlenmesi tutarlı bir sürecin işlerlik kazanması için kampanyada mutlaka bulunması gereken hususlardır (Devran, 2004, 131).

Devine ve Hirt'e göre seçim kampanyalarında üç temel sonuca ulaşmak hedeflenir. Bunlar (Kalender, 2005, 81):

1. Bilgi verme

2. İkna etme

3. Kamu seferberliğidir.

Seçim kampanyası sürecinde hedef kitleye siyasi partiler, adaylar, politikalar, projeler, iktidarın neler yaptığı, muhalefetin nasıl bir siyaset tarzı olduğu, yapılması planlanan çalışmalar hakkında bilgiler verilmektedir. Bu süreçte bilgi aktarımının arkasında yatan sebep, seçmenlerin bir siyasi parti ya da adaya yönelmesini sağlamaktır. Bu yönelme işlemi çeşitli ikna yöntemleri ile yapılmaktadır. Ayrıca seçmenlerin istenilen yönde oy vermesi için her türlü çalışma yapılmakta ve seçmenler istenilen yönde motive edilmeye çalışılmaktadır (Kalender, 2005, 81-82).

Seçim kampanyalarının gerçekleştirildiği zamanlar siyasal iletişimin en yoğun şekilde uygulandığı dönemlerdir. Politikacılar ve danışmanları seçmenleri etkilemek ve onları ikna etmek için çeşitli taktikler uygulamaktadırlar. Seçim kampanyalarının siyasi partiler ve adaylar açısından politikanın doğal akışı içerisinde çok önemli işlevleri bulunmaktadır. Uztuğ, siyasal seçim kampanyalarının işlevlerini şu şekilde sıralamıștır $(1999,18)$ :

1. Seçim kampanyaları öncelikle seçmenleri ikna etmeyi hedeflemektedir. Seçmenlerin istenilen yönde oy kullanması için vatandaşların tercihlerini değiştirmek amaç edinilmiştir. Eğer seçmen verilen mesajla aynı fikri paylaşıyorsa bu noktada var olan tutumların güçlenmesi istenilmektedir.

2. Kampanyalar, adaylar ve partiler arasındaki farkın ortaya çıkmasına zemin hazırlarken seçmenlerin kolay tercih yapmasına yol açmaktadır.

3. Vatandaşların hali hazırda bulunan siyasal sisteme sadık kalmaları sağlanmakta ve demokrasinin standartlarının yükselmesine katkı sağlanmaktadır.

4. Kamuoyunun tüm fikirleri konuşarak, düşünceler arasındaki farklılıkları görmesini sağlamaktadır.

5. Liderlerin ve adayların tanıtımı yapılmakta ve halkın gözünde politikacıların meşru bir zeminde oldukları ispatlanmaktadır.

6. Kampanyalar, partilerine ve adaylarına olumlu bir imaj çizerken muhtemel rakiplerini de eleştirerek itibarsızlaşmalarına neden olmaktadır.

7. Seçim dönemlerinde medya organlarında ülkedeki çeşitli sorunlar ve/veya hizmetler gündeme taşınarak kamuoyunun tüm gelişmeler hakkında bilgi sahibi olması sağlanmaktadır.

Türkiye özelinde seçim kampanyalarına bakıldığında iktidar partisi ya da partileri ile muhalefet partileri arasında çok ciddi boyutlarda kavgalar, gerginlikler ve sorunlar yaşanmaktadır. İktidar partisi ya da partileri devletin gücünü kullanarak popülist davranmakta, muhalefet partileri ise proje üretmek yerine iktidarı eleștirmek üzerine kurulu bir seçim kampanyasına yönelmektedirler (Özkan, 2007, 122)

\section{Siyasal Kültür Yaklaşımı}

Siyaset, devlet olgusu çerçevesinde ve devlet olgusuna ilişkin bir faaliyet alanına sahiptir. Siyasetin özünde iletişim vardır. Kapani`ye göre, siyaset, zaman ve mekan 
bakımından evrensellik ve süreklilik niteliklerine haizdir. Siyasetin nüvesi toplumdaki değerlerin dağıtımıyla ilgili bir görüş ve çıkar çatışmasına dayanmakla birlikte, bir iktidar mücadelesini de kapsamaktadır. Siyaset, salt bir çatışma değil, aynı zamanda bir uzlaşma sanatıdır. Siyaset diğer bir ifadeyle politika, bireylerin hayatlarını çok yakından ilgilendiren ve onların hayatlarını şekillendiren bir faaliyettir. Aristo'ya göre siyaset, insanlığın genlerinde olan toplumsallığın, başka bir deyişle hemcinsleriyle iletişim kurma ihtiyacı ve yeteneğinin bir uzamı olarak belirmektedir (Aristoteles, 2007; Kapani, 2013, 19, 21; Yavaşgel, 2004, 1, 140; Vergin, 2003, 21). Platon, devlet adlı eserinde, yöneten ve yönetilen ayrımına değinmiștir: Toplumu yönetecek kişilerin yaşlılar arasından ve onların da en iyilerinin tercih edilmesi gerektiğini, en akıllı ve toplumla yakından ilgilenen kişilerin aynı zamanda ömürleri boyunca toplumun yararına işler yapmış, toplumun zararına olabilecek şeylerden kaçınmış olması gerektiğini $(2012,107)$ belirtmiştir.

Kelime anlamı olarak kültür, yetiştirmek veya bakmak manasında klasik Latin dilindeki 'colere' veya 'cultura' fiillerinden gelmektedir. 'Cultura' ilk kez Voltaire tarafından insan aklının oluşumu, gelişimi ve geliştirilmesi anlamında kullanılmıștır (Soydaș, 2010, 31). Walter J. Ong (2010) 'Sözlü ve Yazılı Kültür' adlı kitabında kültürün öncelikle sözlü gelenekten geldiğini, daha sonra yazılı kültürün oluşmasının ardından teknolojik devrim ile sözlü ve yazılı kültür arasındaki ayrımın üzerine gidildiğini, bugün yaşanılan kültürün teknolojinin de etkisiyle 'ikincil sözlü kültür' olduğunu vurgulamıştır. Bunun yanında Ong, içinde bulunduğumuz modern zamanda yazılı kültürün sözelleştirildiğinin altını çizmiştir. Kültür, sosyal hayatın bir parçası olmanın ötesinde bilginin, tercihlerin, uygulamaların ve kurumların tümüne nüfuz ederek onları etkilemektedir. Kültür, sosyal birliğin kendiliğinden bir kaynağı olmaktan ziyade, potansiyel bir çatışma alanı şeklinde gücün ve stratejinin bir unsuru olarak görülmektedir (Jasper, 2010, 127). Özellikle yirminci yüzyılda televizyon, radyo ve sinema gibi kitle iletişim araçlarının yükselişi kitle toplumu tezinin ortaya çıkmasını sağlamıștır. Bu model çeşitli toplumsal katmanlardan geniş kabul görmüştür. Sanayileşme ve kentleşmenin, az çok farklılaşmamış tüketiciler ve vatandaşlar 'kitle'sini yarattığı iddia edilmiştir ve bu insanların zekası küçümsenmiş, sürü psikolojisiyle yaşadıkları, ortak zevkleri olan ve liderlik edilmesi gereken insanlar olduğu kabul edilmiştir (Smith, 2005, 230).

Siyasal kültür, karşılaştırmalı olarak bir siyasal sistemin niteliklerini incelerken açıklayıcı gücü fazla olan bir kavram olarak Gabriel Almond ve Bingham Powel tarafından, 1960'ların başında sunulmuştur. Samuel P. Huntington'un geleceği 'Medeniyetler Çatışması' (Clash of Civilizations) olarak betimlemesi siyasal kültüre olan ilgiyi yoğunlaştırmıştır (Özbudun, Kalaycıoğlu, Köker, 1995, 43). Siyasal kültür, politik unsurlara yönelik olarak, toplumun geniş bir kesimince paylaşılan fikir, tutum ve davranış kalıpları olup, kamu politikalarının oluşturulmasından, siyasal anlaşmazlıkların çözümüne ve siyasal iletişimin biçim ve içeriğine değin birçok faktörü kapsayan psikolojik atmosferi oluşturmaktadır (Oktay, 2002, 16). Demokratik bir siyasal kültür, bir ülkede hayatını devam ettiren tüm bireylerin kendilerini bu ülkenin vatandaşı hissettiği, kişilerin aktif olarak siyasal sürece katkı yapabildiği, sivil toplumun ülkeyi ve halkı ilgilendiren konularda karar mercilerine etki edebildiği, vatandaşların yapması gereken görevlerinin yanında haklarının da çok önemli olduğu bir sistemde mümkündür (Durdu, 2013, 25). Özer Özkaya’ya göre siyasal kültür, insanların içinde yaşadıkları toplumun yönetimiyle ilgili algı, ilgi, bilgi, 
değer ve eylemlerin özellikle otorite sembollerini ve meşruluk ölçütlerini ve bunları etkileyen maddi ve manevi koşullardır (Ozankaya, 2013).

Siyasal kültür toplumsal kültürün diğer ögelerinden ve uluslararası kültürden soyutlanamaz. Siyasal kültür bu unsurlardan etkilenirken aynı zamanda onları etkileme gücüne sahiptir. Siyasal kültürü, bir toplumun ekonomik koşulları, toplumsal kültürün farklı aşamaları ve siyasal sistemde aktif rol oynayan siyasi kadroların dünya görüşleri ve fikirleri de önemli derecede şekillendirmektedir (Turan, 1976, 35, 37). Türkiye'de siyaset geleneksel olarak sağ ve sol şeklinde ikiye bölünmüştür. Süreç içerisinde sağ ve sol kavramlarının temsilcileri kadar fikirlerin muhtevası, bileșenleri, dilleri, uygulamaları değişmiştir. Konjonktüre göre siyasi yelpazedeki sağ-sol ayrımının sınır çizgisi yer değiştirmiş, ancak siyaset sahnesinde de derinlerde yer alan kökleşmiş ve değişmesi uzun zaman ve vizyon gerektiren temel karakteristik özellikler vardır. Bunlardan en önemlisi, hegemonya, ideoloji ve iktidar konuları ayrı tutularak, sağın halkın sözcülüğünü yapması, meşruluk kaynağı olarak halkı görmesi karşısında sol siyaset anlayışı cumhuriyetçidir; bu nedenle bir öncelik ve tercih eğilimi bakımından Türkiye'de sağı 'demokrat' solu ise 'cumhuriyetçi' olarak tasvir etmek olağandır (Bostancı, 1998, 12, 13).

Diğeryandan siyasal kültürde Tekeli (2013)'ye göre bazı dinamiklerön plana çıkmakta ve siyaset yapma geleneği bu dinamiklerden beslenmektedir. Bu dinamikler:

1. Íktidar anlayışı, ülkemizin siyaset anlayışında iktidar ele geçirilen bir yer konumundadır. İktidarı inşa edilecek bir organizma olarak yorumlamak yerine, kazanılacak bir zafer olarak görülmektedir. Bir siyasal parti uzun süre iktidarda kaldığında yaşamın her alanında söz söyleme yetkisini elinde bulundurduğunu düşünmektedir.

2. Kayırmacı, yandaş yaratma, sadakat esaslı siyaset pratiği, kayırmacı, popülist ve kutsallaşan unsurlara dayalı sadakat esaslı bir siyaset yürütülmektedir. Bazı çevrelere siyasal sadakatine ödül olarak ayrıcalık tanınmakta, nüfuzlarını sürdürmelerisağlanmaktadır.Oydevşirmekiçinsorunçözmeyeodaklanmakyerine, toplumun kutsallarına aidiyet göstererek amaçlarına ulaşmaya çalışmaktadırlar. $\mathrm{Bu}$ anlayış da süreç içerisinde tedricen demokrasiyi yaralamaktadır.

3. Geçmişin yorumuna dayalı farklılık yaratmaya çalışan bir siyaset pratiği; geleceğe dair beklentiler üzerinden siyaset yapmamak, siyasal kültürümüzün diğer önemli bir sorunsalıdır. Türkiye'de siyaset geleceğin projelerini tartışarak yapılmamaktadır. Her farklı grup kendi algı dünyasını oluşturmaya çalışarak Türkiye'nin tarihini istediği yönde yeniden yazmaktadır. Problemlerin çözümüne uğraşılmadığı için uzlaşı kültürüne de ihtiyaç duyulmamaktadır. Siyaset halkın sorunlarına çözüm üretme yerine liderin mitini inşa etme üzerine kurulmaktadır. Güçlü liderin çevresinde lidere sadakatla bağlı, yakın gelecekteki siyasal pozisyonların beklentisi içinde kadrolar oluşmaktadır.

Tüm bu unsurlar Türkiye'nin siyasal kültürünün eksi yönleridir. Siyasal kültürün bu tip sorunlarla uğraşması demokrasi, özgürlük ve insan hakları konularında kökleşmiş geleneklerin oluşmasını geciktirmekte ve hatta engel olmaktadır.

Kesitsel yöntemlerle belirlenmesi mümkün olmayan politik, ekonomik ve sosyal süreçler ve olgular kültürü ve buna bağlı olarak da siyasal kültürü etkilemektedir. Siyasal kültürün tam olarak neleri kapsadığını tayin etmek imkansızdır. Siyasal 
kültürün zaman içerisinde nasıl değiștiği görebilmek için dönemsel araștırmalara ihtiyaç vardır, ancak Türkiye'nin siyasal kültürünü ortaya koyacak niceliksel ya da niteliksel araştırmalar çok kısıtlıdır. Fakat bu alanda yeterli araştırma yapılmış olsa bile, araştırmalar değişen siyasal kültür göstergelerini ortaya koyacaktır, ancak bu değişimin nedenlerini açıklamada yetersiz kalacaktır (Turan, 2009, 520, 521). Siyasal kültür ile toplumsal yapı iç içe geçmiştir. Toplumsal değerler ile siyasal kültürün, siyasal iletişim ve siyasal liderlerin imajları arasında yakın bir ilişki olduğu ve birbirlerini besledikleri düşünülmektedir.

Siyasal kültür sürekli bir değişim içinde toplumlara ve kültürlere göre farklı özellikler göstermektedir. Türkiye özelinde siyasal sistemle ve toplumsal gerçekliklerle ilintili olarak cumhuriyetin kuruluşundan bu yana siyasal kültür çeşitli dönemlerde bazı faktörlerin etkisiyle çerçevelenmiştir. Türkiye'de uygulanan seçim kanunu ve siyasal partiler kanunu hukuksal anlamda siyasal kültüre etki ederken, ülkenin yönetim şekli, siyasal sistem, toplumsal dinamikler ve ülkenin ekonomik refah seviye ve iktisadi gelişmişlik siyasal kültürün genel hatlarının oluşmasına zemin hazırlamaktadır.

Ülkelere ve siyasal kültürlere göre değişmekle birlikte, seçkinlerin, elitlerin ya da güç sahiplerinin desteği ve yardımı ile iktidar olanlar, halkın görevlendirmesi ile iktidar olanlara kıyasla daha zor bir durumla karşı karşıyadırlar. Çünkü iktidar olan kişi ya da kişilerle onların etrafında bulunanlar kendilerini hükümdar ile eşit bir seviyede kabul etmektedirler. $\mathrm{Bu}$ nedenle siyasal iktidarlar seçkinlere istediklerini yaptıramaz, onları dilediği biçimde yönlendiremez. Ancak doğrudan halkın yardımı ile iktidar olanlar, daha buyurgan bir tavra sahip olmakta ve daha özgür olabilmektedirler. Ayrıca arkasında halkın desteğini hisseden hükümdara ya da iktidara biat etmeyecek gruplar oldukça azdır (Machiavelli, 2012, 58). Siyasal sistemlerin en önemli ögelerinden biri iktidardır. İktidar, Hume'a göre, öznel bir kategoridendir. Max Weber'e göre ise, belirli bir sosyal ilişki içerisinde, bir bir faile, bu ilişkiyi, çerçeveyi ve muhtevayı kendi planladığı yönde belirme imkanı veren yapıdır. İktidar, ilkel çağlardan bugüne kadar sürekli olarak sosyal bir yapının hizmetindedir ve yapının kendi kendini yönetmesi beklenemez. İktidar denilen olgu, ortak yaşam koşulları hazırlamakta, topluluk halinde yaşayan insanların hayatlarını devam ettirecekleri koşulları oluşturmaktadır (Balandier, 2010, 35).

Siyasi Partiler Kanunu, Türkiye'nin siyasal atmosferini derinden etkileyen ve siyasi partilerin nasıl bir muhtevaya sahip olması gerektiğini anlatan siyasal kültürün en önemli unsurlarından biridir. Kanunun birinci kısmında, siyasi partilerle ilgili esaslar düzenlenirken ikinci kısımda, siyasi partilerin teşkilat yapılarının nasıl olması gerektiği anlatılmaktadır. Bunların dışında siyasi partilerin merkez teşkilatları, il ve ilçe teşkilatları, TBMM'deki siyasi parti grupları, siyasi partilerin seçimlere katılması ve aday tespiti gibi konuların tamamı bu kanun tarafından düzenlenmiştir (2820 Sayılı Siyasi Partiler Kanunu, 1983).

Özbudun ve Hale $(2010,92)$, siyasi partiler kanunu şu şekilde betimlemişlerdir:

1983 yılında o zamanki askeri rejim tarafindan kabul edilmiș olan Türk Siyasi Partiler Kanunu, muhtemelen bütün Avrupa'da bu tür kanunların en ayrıntılı olanıdır. Bu kanun, parti yasaklarının yanında, parti örgütü, üye kaydı, üyelik, aday gösterme, disiplin ve parti finansmanı konularında aşırı derecede ayrıntılı düzenlemeler ihtiva etmektedir. Dolayısıyla bütün Türkpartileri, kanunun kendilerine dayattı̆̆ çokbenzer örgütselyapılara sahiptirler. Buna göre bütün kademelerde başkanlar ve yönetim kurulları, o kademedeki kayıtlı üyelerce seçilen delegelerin oluşturduğu kongreler tarafından seçilmektedir. 
Türkiye'de siyasi partilerin merkeziyetçi ve hiyerarşik bir yapısı vardır. Bunun nedenleri arasında Siyasi Partiler Kanunu bulunmakla birlikte asıl neden Türk siyasal kültür geleneğidir. Bu bağlamda yerel örgütler ihmal edilmediği takdirde, büyük oranda merkezi organların ve yöneticilerin tahakkümündedirler. $\mathrm{Bu}$ sınırları belirlenmiş yapı kapsamında partileri diğerlerinden ayıran özellikleri biçimsel nitelikleri yerine örgüt kültürleri olmuştur. Türk siyasi partilerin bir kısmı kliyentalist (yönetimi ele geçirmeye çalışan himaye sistemi) özellikler taşıyan, kartel, kadro ve herkese açık partilerin birtakım niteliklerini kendilerinde birleştirmeyi başarmışlardır (Özbudun ve Hale, 2010, 94, 95).

Toplulukçu kültürün de siyasal kültür üzerinde önemli bir etkisi vardır. Bu bağlamda Freud (1996, 15)‘a göre, birey kitle içinde davranışlarının bilincinde olmaktan çıkmakta, hipnotize edilen kişide olduğu gibi bazı yetenekleri işlevsizleşirken bazı yetenekleri enikonu güçlenmektedir. Bu fikirler çerçevesinde Türkiye, dünya ile aynı düzlemde gitmek için 1983'ten itibaren küresel değişimlere ve topluluklara daha yoğun ilgi göstermeye başlamıştır.

Türkiye'nin siyasal kültür dinamikleri diğer ülkelere kıyasla farklı özellikler göstermektedir. Siyasal kültürün geçmișten bugüne devam eden ve konjonktürel olarak değişebilen nitelikleri çeşitli dönemlerde birtakım unsurları barındırmaktadır. Türkiye'nin siyasal kültürü analiz edilirken Osmanlı'nın etkisini unutmamak gerekir. Askeri darbeler, Anayasa Mahkemesi'nin kapatılması yönünde karar aldığı siyasal partiler, üst mahkemelerin yürütmeyi durdurma kararları, sekülerleşen toplumda laikliğin yansımalarının değişmesi ve siyasal parti teşkilatlarının siyasal kültür algısı Türkiye'deki siyasal iklimin başlıca sorun alanlarını oluşturmaktadır.

\section{Genel Seçimlerinde ANAP'ın Seçim Kampanyası}

Fransız reklamcı Jacques Seguela'yı Türkiye'ye getiren ANAP, Seguela ile anlaşmış ve 1991 Genel Seçimlerinde tüm seçim stratejisini ve seçim kampanyasını Seguela'nın hazırlamasına onay vermiştir (Çankaya, 2008, 207). Seguela, Fransa'da kendi reklam ajansı olan Roux, Seguela, Cayzac ve Goudard (RSCG) isimli şirketi ile yurt dışında çeşitli reklam kampanyaları yapmıştır, ancak ilk kez ANAP için Türkiye'de bir siyasal iletişim kampanyası gerçekleştirmiştir (Topuz, 1991, 44). 1991 seçimleri Türkiye'de siyasal iletişim alanı için yeniliklerin yaşandığı bir seçim olmuştur. Seçimlere katılan bütün siyasal partiler reklam ajansları ile anlaşarak seçim kampanyalarında profesyoneller ile ortaklık kurmuşlardır. Seguela ve ajansı RSCG, o dönemde Türkiye'de Ena iletişim tarafından temsil edilmiştir (Özkan, 2014, 130, 132).

İthal bir reklamcı olan Seguela'nın ANAP'ın seçim kampanyasını üstlenmesi Türkiye'de büyük bir gündem yaratmıștır. Seguela'nın Fransa'da önemli başarılara imza atmasına rağmen, Türkiye'nin siyasal atmosferini tanımadığı ve Türk insanının kültürel yapısına hakim olmadığı eleştirileri yüksek sesle dile getirilmiştir. 0 dönemde reklamcılar; seçimlerin hem ulusal hem yerel karakter taşıdığını, ayrıca sosyo-psikolojik bir olay olduğunu, seçmenlerin beklentilerinin ve fikirlerinin Türkiye'de yaşayan reklamcılar tarafından analiz edilebileceğini, ithal bir reklamcının Türkiye'de hiçbir pazarlama ve reklam deneyimi olmadan yapacağı kampanyanın başarı şansının son derece az olduğunu vurgulamışlardır (Topuz, 1991, 45). Çok ciddi eleştiriler almasına karşın Seguela'nın ilk olarak ANAP'ın genç lideri Mesut Yılmaz'a on hayati öneri sunarak işe başladığı basın yayın kuruluşlarına yansımıştır. Bu öneriler ise şunlardır (Seguela, 1997, 38; Özkan, 2014, 132, 133): 
1. Seçimleri ideoloji değil lider kazanır.

2. Seçimlerde geçmiş değil, gelecek için oy verilmektedir.

3. Seçim siyasal olmaktan çıkarak psikolojik bir olaya dönüşmüştür.

4. Oy umut için verilir, siyasal partilerin programı için değil.

5. Lider, bağımsız bir kişiliği olduğunu seçmenlere göstermelidir.

6. Devlet adamı olmak isteyen politikacılar kendi efsanelerini geliştirmelidirler.

7. Lider, yerel imajının ötesinde uluslararası imajına da önem vermeli ve bunu geliştirerek parlatmalıdır.

8. Devlet adamı geleceği planlamalı, ülkesinin temel niteliklerini yansıtmalı, bugünden yarını temsil etmelidir.

9. Seçimleri lider kazanır, fakat lider yalnız olmadığını unutmamalıdır ve politika dışındaki ilişkilerine değer vermelidir.

10. Zamana zaman tanımak gerekir. Lider orta ve uzun vadeli düşünerek politika geliştirmeli ve bu fikirlerini söylemleri ile ortaya koymalıdır.

ANAP el ilanlarından afişlere, gazete ve dergi ilanlarından televizyon reklamlarına, stickerlardan mektuplara, dövizlerden açıkhava reklamlarına kadar çok sayıda mecrayı ve materyali seçim çalışmalarında kullanmıştır. Gelişen teknolojinin sunduğu firsatlar arasında olan video ve ses kasetleri de birçok seçim bölgesinde kullanılmıştır. 20 Ekim 1991 tarihinde gerçekleşen seçimlerin medya planlamasını Magix Box yapmıştır. Magix Box’ın planına göre Mesut Yılmaz ekranlara çıkarak kendisi için oy istemiştir ancak bu zamanlama açısında ekim ayının başında gerçekleştirilmiştir. Seguela tüm kampanyayı ve siyasal iletişim çalışmalarını Mesut Yılmaz üzerine inşa etmeyi tercih etmiştir. ANAP'ın 8 yıllık iktidarı dolayısıyla TRT'de, Ahmet Özal'ın Magix Box şirketinde Uzan grubu ile ortaklığı sebebiyle de Star-1 TV'de ANAP'ın televizyon reklamları daha fazla yayınlanmıştır (Özkan, 2014: 135, 137).

ANAP'ın seçim mitinglerinde Genel Başkanı Mesut Yılmaz, sahneye çıkmadan önce o dönem için yeni bir uygulama olarak çeşitli sanatçıların mitinge gelen kalabalığa konser vermiştir. Böylece lider sahneye çıkmadan önce meydandaki kalabalığın artması ve halkın güzel vakit geçirmesi sağlanmaktadır.

Seguela'nın bütün afişlerinde lider ön plandadır. Siyasal iletişim stratejisinde Seguela için en önemli nokta lider olmuştur (Topuz, 1991: 10). Siyasal partiler ideolojileriyerine liderlerini kristalize etmekte, liderlerin vasıfları ve karizmaları üzerinden seçmenlere mesaj göndermek için lider imajına çeşitli anlamlar yüklemekte liderlerin semboller kullanmasını, yöresel deyişlere konuşmalarında yer vermesini sağlamaktadır.

\section{Yöntem}

Çalışma, kalitatif bir araştırma olması sebebiyle hipotezler belirlemek yerine araştırma soruları tespit edilmiş ve bu sorular çerçevesinde çalışma şekillendirilmiş ve sorulara yanıt aranmıştır. Araştırmada, "Kültürel unsurlar seçim kampanyalarında verilen siyasal mesajların şekillenmesinde rol oynamaktadır" önermesinden yola çıkılarak “1991 Genel Seçimlerinde ANAP'ın seçim kampanyasında siyasal kültürden nasıl yararlanılmaktadır?" sorusuna cevap aranmaktadır. Metodolojik olarak çalışma kapsamında cevap aranan alt amaç soruları şu şekildedir:

1. Türkiye'de nasıl bir siyasal kültür atmosferi hakimdir?

2. Siyasal kültürün siyasal iletişim alanına yansımaları nasıl olmaktadır?

3. Siyasal liderlerin imajlarında hangi siyasal kültür nitelikleri bulunmaktadır? 
4. Siyasal kültürün hangi bileșenleri siyasal iletişim sürecinde ikna unsuru olarak kullanılmıştır?

5. Siyasal mesajların taşıdığı kültürel unsurlar ve yerel nitelikler nelerdir?

6. Basın ilanlarında ve siyasal reklamlarda yer alan siyasal kültür kodları nelerdir?

Buçalışmabetimselanalizyöntemikullanılarakgerçekleştirilmiştir.Öncelikleliteratür taraması yapılarak siyasal iletişim, siyasal reklam ve seçim kampanyalarıyla ilgili gerekli teorik alt yapı oluşturulmuştur. Ağırlıklı olarak niteliksel içerik çözümlemesi tekniği kullanılmıştır. İlgili literatürden yararlanılarak tema çözümlemesine başvurulmuş ve betimleyici bir analiz yapılmıştır. Çalışma, ANAP'ın 1991 seçim kampanyasıyla sınırlandırılmıştır. Zaman açısından çalışma 20.09.1991-20.10.1991 tarihleri arasında gerçekleștirilmiştir. Araştırmada, ANAP'ın seçim beyannamesi içerik analizi tekniğiyle incelenmiş ve oluşturulan kategorilere göre beyannamedeki mesajlar anlamlı hale getirilmiştir. Bu kategoriler siyasal iletişim uzmanı iki öğretim üyesinin onayı alınarak çalışmaya dahil edilmiştir. Gazete ilanlarında en fazla tekrar edilen kavramlar aynı zamanda gazete ilanlarındaki kodlar olarak belirlenmiştir. ANAP'ın seçim kampanyasında yer alan 9 gazete ilanına, 3 seçim şarkısına ve 4 televizyon reklamına içerik analizi uygulanmıştır.

\section{Bulgular}

\section{ANAP'ın Seçim Beyannamesinin İçerik Analizi}

1991 Genel Seçimleri öncesinde yayınlanan seçim beyannamesi toplam 102 sayfadan oluşmaktadır. Seçim beyannamesi, ANAP'ın sekiz yıllık süreçte Türkiye için neler yaptığından, gelecek dönemdeki hedeflerinden ve vaatlerinden oluşmaktadır.

Tablo 1: 1991 Genel seçimleri ANAP'ın Seçim Beyannamesinin Niceliksel İçerik Analizi

\begin{tabular}{|l|c|c|}
\hline Mesaj & Sayı & Oran \\
\hline Küresel mesajlar & 35 & $\% 6.74$ \\
\hline Ulusal hizmetler & 100 & $\% 19.26$ \\
\hline Ulusal projeler & 64 & $\% 12.33$ \\
\hline Ulusal vaatler & 205 & $\% 39.49$ \\
\hline Bölgesel (yerel) hizmetler & 1 & $\% 0.19$ \\
\hline Bölgesel (yerel) projeler & 5 & $\% 0.96$ \\
\hline Bölgesel (yerel) vaatler & 3 & $\% 0.57$ \\
\hline Güncel konulara atıf & 83 & $\% 15,99$ \\
\hline Siyasal figürlere atıf & 1 & $\% 0.19$ \\
\hline Siyasal tarihe atıf & 19 & $\% 3.66$ \\
\hline Muhalefete eleştiri & 3 & $\% 0.57$ \\
\hline Toplam & 519 & $\% 100$ \\
\hline
\end{tabular}

Mesut Yılmaz’ın önsözü ile başlayan beyannamede gazete ilanında olduğu gibi Yılmaz, seçmenlere 'aziz vatandaşlarım' şeklinde hitap etmektedir. Siyasal tarihe yapılan 19 atıf incelendiğinde, göndermelerin büyük çoğunluğunda geçmişte yapılan yanlışlar, eksiklikler ve hatalardan bahsedildiği görülmüştür. Siyasal tarihle ilgili olumlu anlamda atıf yapılan tek nokta Mustafa Kemal Atatürk'ün icraatlarıdır. Siyasal figürlere yalnızca bir kez değinilmiş, Adnan Menderes, Hasan Polatkan ve Fatin Rüștü Zorlu'ya iadeyi itibar yapıldığı, bu siyasal figürlerden saygıyla bahsedildiği görülmüştür. 
Verilen mesajların \% 70.98'i ulusal düzeydeyken yalnızca \% 1.72'si bölgesel (yerel) düzeydedir. Seçim beyannamesindeki bölgesel (yerel) mesajlar incelendiğinde, toplamda 9 mesaj verilmiştir ve mesajların 8'i Doğu ve Güneydoğu Anadolu Bölgeleri ile ilgiliyken sadece bir mesaj spesifik olarak İstanbul'un yönetim şeklinin değiştirileceği konusuyla alakalıdır. Bölgesel mesajlar tahlil edildiğinde, Güneydoğu Anadolu Projesi'nin geliştirilmesi, tamamlanması ve bölgeye sağlayacağı katkılara odaklanıldığı sonucuna ulaşılmıştır.

35 küresel mesaj incelendiğinde, bu mesajların önemli çoğunluğunun dış politika ana başlığı altında verildiği görülmüştür. Ayrıca gazete ilanlarındaki Türkiye vurgusu, dış politika konusunda da aynı dozda devam ettirilmiştir. Seçmenler ve özellikle iş hayatının içinde olan vatandaşlar çeşitli kategorilere ayrılarak doğrudan onları ilgilendiren konularda mesajlar verilmiştir. Örneklem olması açısından esnaf ve sanatkarlara yönelik olarak yapılacak iyileștirmelerden, destek ve diploma imkanlardın söz edilerek bu ve benzeri şekilde farklı sosyo-ekonomik seviyeye sahip vatandaşların beklentilerinin siyasal mesajlarla karşılanmaya çalışıldığı görülmüştür.

Seçim beyannamesi incelendiğinde, dönemin iktisadi anlamda en önemli siyasal kültür unsurunun özelleștirme konusu olduğu sonucuna ulaşılmıştır. Ulusal ve bölgesel (yerel) hizmetler, projeler ve vaatler analiz edildiğinde en fazla ekonomi konusuna yer ayrılmıştır. Ekonomik kalkınma ve ihracatın artırılması 1990’ların başında ekonominin en önemli satır başları olarak ortaya çıkmaktadır. Bu çerçevede gayri safi milli hasıladan en büyük payı orta ve alt gelir grubunun alması hedefinin ekonomideki birincil öncelik haline geldiği sonucuna ulaşılmıştır.

Sağlık alanında dönemin en belirgin siyasal kültür kodu hiçbir ayrım gözetmeksizin tüm vatandaşların sosyal güvenceye kavuşturulmasıdır. Eğitim alanındaki dominant siyasal kültür kodu ise eğitim alanlarının fiziksel şartlarının iyileştirilmesi ile öğrencilerin yurt dışında eğitim alması için burs imkanlarının oluşturulmasıdır. Spor alanındaki belirgin siyasal kültür kodunun, spor tesislerinin sayılarının artırılması olduğu sonucuna varılmıştır.

\section{ANAP'ın Gazete İlanlarının İçerik Analizi}

1991 seçim kampanyasında ANAP 9 gazete ilanı yayınlamıştır. Seçim kampanyası çerçevesinde Seguela, Mesut Yılmaz'ın tek bir fotoğrafını kullanmayı uygun görmüştür.

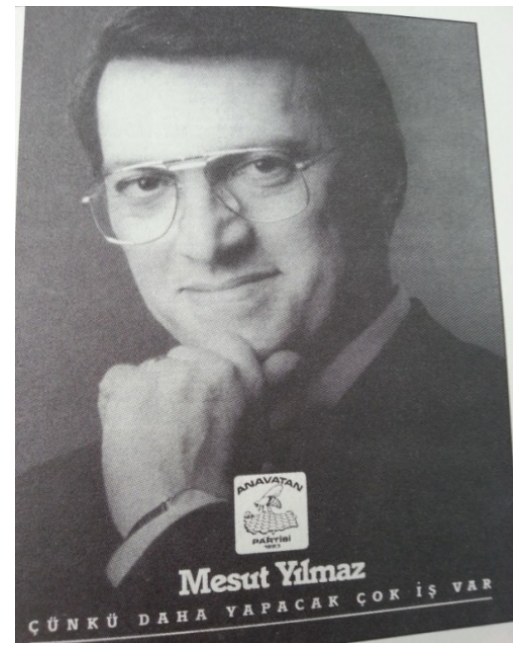

Şekil 1: 1991 Genel Seçimleri ANAP Gazete İlanı 
Mesut Yılmaz'ın tam karşıdan çekilen fotoğrafı ile düzgün taranmış saçları, gözlükleri, hafif tebessüm etmiş yüz ifadesi ve elini çenesine koyduğu bu kareyle güvenilir, kendinden emin bir politikacı imajı çizmeye çalışılmaktadır. Bu fotoğraf kampanyanın ortak paydasıdır ve kampanya süresince verilen 9 gazete ilanının 8'inde bu fotoğraf kullanılmıștır. Her gazete ilanında farklı bir başlık kullanılmıștır, ancak Mesut Yılmaz'ın fotoğrafı, ANAP'ın amblemi ve seçim kampanyasının sloganı 'Çünkü daha yapacak çok işimiz var' cümlesi dokuz gazete ilanının sekizinde yer almıştır ve sloganın akılda kalıcılığı için tutarlı bir yol izlenmiştir. Ayrıca dokuz gazete ilanının yalnızca birinde Mesut Yılmaz isminin altında başbakan ve Anavatan Partisi Genel Başkanı unvanları yer almıştır. Seçim kampanyasında stratejik olarak adayı temel alan siyasal reklamlar kullanılmıştır, ancak gazete ilanları incelendiğinde bazılarının içeriğinin toplumsal gruplara yönelik siyasal reklamlar, bazılarının ise negatif siyasal reklamlar olduğu sonucuna ulaşılmıştır. Bu gazete ilanlarının metinlerinde yapılacak çalışmalar ve vaatler yer almaktadır, bunun yanında ANAP'ın hedeflerinden bahsedilirken mutlu toplum tasavvuru konu edinilmiștir. Gazete ilanlarında mesajlar yumuşak bir dil kullanılarak seçmenlere iletilmiştir.

"Türkiye çağı yakalamak için dünyaya açılmayı sürdürecekse...," "Türkiye, her vatandaşına sosyal güvence sağlayacaksa..., "Türkiye'de çalışan herkes emeğinin karşılığını alacaksa...", "Türkiye dünyaya açılırken kendi öz değerlerine sahip çlkacaksa...", "Türkiye gençlerine eğitim ve iş imkanı sağlayacaksa...", "Türkiye'de kadınlar hak ettikleri yere gelecekse..., "Türkiye'de, hızlı gelişmenin devamı için siyasi istikrar şartsa..., "Türkiye'de barış ve hoşgörü siyasete hakim olacaksa..” Başlıklarını taşıyan sekiz gazete ilanı Mesut Yllmaz ismiyle tamamlanarak bitirilmektedir. 'Çünkü daha yapacak çok iş var' sloganı sekiz gazete ilanının hepsinde Mesut Yılmaz isminin altında yer almıştır. Kampanya kapsamında verilen dokuz gazete ilanında da uzun metinler kullanılmıştır. Ve bu ilanlarda Seguela'nın çektirdiği ve seçim kampanyasının her aşamasında kullanılan fotoğraf yer almıştır.

Gazete ilanlarının içeriğinin çok uzun olması, Türkiye'de vatandaşların okuma alışkanlığı ile bağdaşmamaktadır. Okuma kültürü çok fazla olmayan Türk insanı için bu kadar uzun metinlerin yer aldığı gazete ilanlarının seçmenlerin ilgisi çektiğini söylemek güçtür. Bu noktada kampanyanın yürütücüsü Seguela'nın gazete ilanlarındaki metinleri bu kadar uzun tutmasını Türkiye'de halkın okuma kültürünü bilmemesine bağlamak mümkündür. Fransa'daki okuma alışkanlığı ile Türkiye'deki okuma alışkanlığının benzer kabul edilerek gazete ilanlarında metinlerin görsel unsurlardan baskın olması kararının yanlış olduğunu söylemek yanlış olmayacaktır.

Tablo 2: ANAP'ın Gazete İlanlarına Göre Dönemin Siyasal Kültür Kodları

\begin{tabular}{|l|c|}
\hline En çok değinilen kavramlar & Sayı \\
\hline Türkiye & 73 \\
\hline Çağdaş ülkeler seviyesi & 34 \\
\hline Genç/Gençlik & 26 \\
\hline Demokrasi & 25 \\
\hline Kalkınma & 13 \\
\hline Toplam & 171 \\
\hline
\end{tabular}

1990'ların başında artan terör olayları siyasetin ve toplumun gerilmesine, çeşitli alanlarda Türk-Kürt ayrımlarının yapılmasına neden olmuştur. Türk Silahlı Kuvvetleri'nin PKK ile mücadelesi Kürt kökenli vatandaşların yoğun olduğu Doğu ve 
Güneydoğu Anadolu Bölgeleri'nde birtakım sorunların oluşmasına neden olmuştur. Dönemin siyasal ve sosyolojik gerçeklerine bakıldığında ANAP'ın gazete ilanlarında çok baskın şekilde Türkiye kavramının kullanılması dikkat çekicidir. Etnik kökenin bir ötekileștirme unsuru olma potansiyeli nedeniyle ve Türkiye'nin birliğini ve beraberliğini vurgulamak amacıyla Türkiye kavramı gazete ilanlarının birincil unsuru olmuştur.

ANAP'ın serbest piyasa ekonomisi ve liberal politikaları çerçevesinde gazete ilanlarında yer alan dönemin en belirgin siyasal kültür kodu "çağdaş ülkeler seviyesine ulaşma" hedefi olarak belirmektedir. İlanlarda yer alan genç/gençlik kavramı Türkiye'nin genç nüfus potansiyeli, ANAP'ın genç kadrosu ve ANAP'ın genç liderini ön plana çıkarmaktadır. Bu noktada ilk kez oy verecek genç seçmenin ilgisini ANAP'a çekme gayreti görülmektedir. Gazete ilanlarındaki diğer önemli kavram ise demokrasidir. Demokratik değerlerin ön plana çıkarılması, demokrasinin standartlarının yükseltilmesi dönemin diğer bir siyasal kültür göstergesi olarak belirmektedir. Çağdaş ülkeler seviyesine ulaşma isteği beraberinde Türkiye'nin kalkınmasını da sağlayacaktır. Bu süreçte iktisadi ve sosyal anlamda ANAP'ın siyasi perspektifi siyasal iletişim uygulamalarında kalkınmayı vurgulamaktadırlar.

\section{ANAP'ın Televizyon Reklamlarının İçerik Analizi}

Televizyon reklamlarında Seguela hiç tasvip etmediği negatif reklamcılıktan yararlanmayı tercih etmiştir. ANAP'ın basın ilanlarında verdiği proje ve hizmet temelli mesajın aksine televizyon reklamlarında rakiplerinin olumsuz taraflarını önceleyen, geçmişe yönelik negatif hatırlatmalar yapılan iki reklam yayınlanmıştır. Burada ANAP'ın Özal ile gerçekleştirdiği başarıları sergilemek yerine rakiplerinin 1970’li yıllarda ülkeyi soktukları kötü durumu mesaj olarak vermeyi tercih eden Seguela, siyasal kültürde yer alan pozitif olaylar yerine negatif gerçekler ile seçmenlere; geçmişe dönmek istemiyorsanız Mesut Yılmaz'ı dolayısıyla da ANAP'ı tercih edin mesajını vermeye çalışmıştır.

ANAP iki tane negatif televizyon reklamının ardından birkaç reklam daha yayınlanmıștır. Sezen Aksu'nun 90'ların başında popüler olan 'Hadi bakalım kolay gelsin' adlı şarkısına yeni sözler yazılarak "Hadi bakalım sandıklara, iki binli yıllara, 20 Ekim Pazar günü bütün oylar ANAP'a” nakaratıyla Mesut Yılmaz'ın kampanyanın her aşamasında kullanılan fotoğrafı ile montajlanarak televizyon reklamına dönüştürülmüştür.

\section{ANAP'ın Seçim Şarkılarının İçerik Analizi}

1991 Genel Seçimleri öncesinde ANAP seçim kampanyasında önemli bir bölümü seçim şarkılarına ayırmıştır. Dönemin en gözde sanatçılarıyla birlikte hareket eden ANAP, seçim şarkılarını miting meydanlarına gelen vatandaşların coşkusunu artırmak amacıyla sürekli olarak kullanmıştır. "Anaplıyız Anaplı biz çok farklıyız çok farklı, hem güçlüyüz hem haklı vatan için hayırlısı. Anaplıyız Anaplı azimliyiz kararlı, Mesut Yılmaz bizimle iktidara kanatlı, Ne boş vaat ne yalan ne kursağında haram Mesut Yılmaz başbakan" nakaratıyla göze çarpan şarkı o dönemde Yonca Evcimik'in 'Abone' şarkısına yeni sözler yazılarak popülist bir tavırla seçim şarkısına dönüştürülmüştür.

Sezen Aksu'ya ait olan 'Hadi bakalım kolay gelsin' parçasının seçim döneminden önce halkın büyük beğenisini kazanması bu şarkının seçim şarkısı olarak tercih 
edilmesindeki en büyük etlen olarak gözükmektedir. Bu parçaya yeni sözlerin yazılmasının ardında şarkının zaten popüler olan müziği yeni sözleriyle de hafızalarda yer etmiștir. "Hadi bakalım sandıklara, iki binli yıllara, 20 Ekim Pazar günü bütün oylar ANAP'a" nakaratıyla seçmenlere seslenen ANAP, seçim kampanyasındaki genel stratejisinin aksine seçim şarkılarında Mesut Yılmaz'ı değil ANAP'ı öne çıkarmıştır. Seçim stratejisine ve gazete ilanlarının içeriğiyle tamamen zıt bir yaklaşım sergilenmiştir. Seçmenlerden oy istemek dışında seçim şarkısının hiçbir vaadi bulunmamaktadır. Seçmene doğrudan ya örtük herhangi bir mesaj vermemekte yalnızca oyların ANAP'a verilmesi istenmektedir.

İzel-Ercan Saatçi ikilisinin parçası olan "Eller havaya" şarkısı "haydi bütün oylar ANAP'a" şeklinde yeniden yorumlanmıştır. Seçim şarkıları seçmenleri oy verme davranışı konusunda motive etmeyi amaçlamaktadır. Kitle kültürünün ürünleri olan pop şarkıları, seçim müziklerine dönüştürülerek kolayca tekrar edilebilen ve akılda kalıcı olan sözler ile seçmenlerin ikna edilmesi hedeflenmiştir. Hala melodisi birçok kişinin aklında olan bu nakaratlar ANAP adına sempatik bir hava oluşturmasına rağmen seçim sonuçlarına bakıldığında seçim şarkılarına gösterilen ilginin oya dönüşmediği görülmüştür.

\section{Siyasal Kültür Düzleminde ANAP'ın Siyasal İletişim Uygulamalarının Değerlendirilmesi}

1991 Genel Seçimlerinde ANAP'ın başarısız olduğu konu, algı yönetimine yeterli önemin verilmemesidir. Güçlü muhalefet liderleri karşısında ve kitle iletişim araçlarının yüz yüze iletişim kadar geçerli olduğu bir dönemde ANAP'ın siyasal iletişim çalışmaları daha etkin ve aktif olabilirdi. Toplum içindeki geniş kitlelere yönelik olarak vaatler ve mesajlar hazırlanmasına karşın, bu mesajların gerekli kültürel kodlarla desteklenmesinde zayıf kalınmıştır.

Magic Box'ın medya planlamasına göre ekim ayının başında Mesut Yılmaz'ın televizyon ekranlarından kendisi için oy istemesi, ANAP'ın kitle iletişim araçlarını kullanmakta geç kaldığını göstermektedir. Seçim kampanyalarının günümüzde fiili olarak seçimlerden bir buçuk ay önce başladığı düşünülürse, ANAP'ın seçim kampanyasını stratejik olarak daha erken başlatılması iktidar partisini avantaj sağlayacaktır. ANAP'ın sekiz yıllık iktidarı süresince neler yapıldığının ve gelecek dönem için yapılacak projelerin siyasal mesaj olarak verileceği seçim dönemi Seguela'nın kararı sonucunda olması gereken süreden daha kısa tutulmuştur. $\mathrm{Bu}$ nedenle seçmenler ANAP'ın seçim kampanyasına daha kısa süre maruz kalmışlardır. ANAP teșkilatının ve ANAP'ın siyasal kadroları ile partinin önde gelen kişilerinin seçim kampanyasında hiç kullanılmaması ANAP'ın en büyük eksiklerinden biri olarak gözükmektedir. Henüz yeni bir lider olan Mesut Yılmaz üzerine kurulan seçim kampanyanın televizyon reklamlarındaki negatif göndermeler dışında Türkiye’nin tarihsel arka planından ve siyasal geçmişinden bahsetmemesi seçmenlerin partinin tarihsel bağlarından uzaklaşmasına neden olmuştur.

Tablo 3: ANAP'ın Seçim Kampanyasında Öne Çıkan Siyasal Mesajlar

\begin{tabular}{|l|l|}
\hline İnceleme Alanları & Öne Çıkarılan Siyasal Mesaj \\
\hline Seçim Beyannamesi & Ekonomik kalkınma \\
\hline Televizyon Reklamları & Muhalefete eleştiri \\
\hline Gazete İlanları & Çağdaş ülkeler seviyesine ulaşma \\
\hline Seçim Şarkıları & Mesut Yılmaz ve ANAP \\
\hline
\end{tabular}


Seguela yönetimindeki kampanya çerçevesinde verilen gazete ilanlarının çok uzun metinler içermesinin 1990'lı yıllarda okuma alışkanlığı düşük olan Türk toplumuna uygun olduğunu söylemek güçtür. Seguela'nın Fransızların okuma alışkanlıkları ile Türklerin okuma kültürünü benzer kabul ederek uzun metinler tercih etmesini yanlış bir karar olarak nitelemek mümkündür. Türkiye'de görsel kültürün yaygın olması ANAP ilanlarının çok fazla ilgi çekmemesine neden olmuştur. Fransız bir reklamcının Türkiye'nin kültürel özelliklerini dikkate almadan gereğinden fazla uzun metinler kullanması gazete ilanlarının seçmenleri etkileme gücünü azaltmıştır. Seçim kampanyasına genel bir perspektif ile yaklaşıldığında Mesut Yılmaz'ın bir star olarak sunulduğu görülmektedir. Yılmaz'ın öne alındığı ANAP'ın geri planda bırakıldığı bir strateji tercih edilmiştir. Gazete ilanlarında Mesut Yılmaz'ın fotoğrafı oldukça baskın şekilde kullanılırken ANAP'ın amblemi çok küçük boyutlarda yer almıştır. Siyasal kültür açısından lider odaklı olan Türk toplumuna, doğru noktadan temas edildiği düşünülmekle birlikte, halkın Yılmaz'ı henüz tam anlamıyla tanımaması ve ANAP'ın sekiz yıllık iktidarı süresince yıpranmasının yanında, ANAP mensupları hakkındaki yolsuzluk ve usulsüzlük iddiaları Seguela'nın kampanyanın başında verdiği on öğütten biri olan 'Seçimi lider kazanır tezini kısmen geçersiz kılmıştır.

Bir sağ parti olarak konumlanan ANAP'ın seçim kampanyasında özellikle muhafazakar seçmenlerden takdir alan ANAP'ı kuran ve iktidara getiren, Türkiye'nin siyasal kültüründe çok önemli siyasal aktörlerden biri olarak kendini cumhurbaşkanlığına taşıyan eski başbakan Turgut Özal'a seçim kampanyasında hiç atıf yapılmaması Seguela'nın Türkiye'nin siyasal kültüründen doğru şekilde beslenemediğini ortaya koymaktadır. Buradaki stratejide, 1983 sonrası siyasal kültürün belirleyici unsurları arasında gösterilebilecek Özal'ın liberal politikaları ve siyasal bakış açısı Yılmaz'ın vizyonu olarak sunulmuştur. Seguela, yeni lider Mesut Yılmaz'a yoğunlaşırken geçmiş dönem göz ardı etmiş sanki yeni bir siyasal parti ve yeni bir lider doğuyormuş algısı oluşturulmaya çalışmıștır.

\section{Sonuç}

ANAP'ın seçim beyannamesi, gazete ilanları, televizyon reklamları ve seçim şarkıları incelenerek kültürel kodlardan faydalanma biçimleri araştırılmıștır. 1991 seçimlerindeANAP'ın Fransız reklamcısıSeguela'nın yürüttüğüseçimkampanyasında Türkiyenin o dönemki siyasal kültürünün ve Türkiye'deki yerel kültürel özelliklerin kampanyada kısmen yer aldığı sonucuna ulaşılmıştır. Bu nedenle çalışmanın başında sorulan "Siyasal mesajların taşıdığı kültürel unsurlar ve yerel nitelikler nelerdir?" sorusuna ANAP’ın seçim kampanyası cevap verememektedir.

"Kültürel unsurlar seçim kampanyalarında verilen siyasal mesajların şekillenmesinde rol oynamaktadır" önermesini ortaya atan çalışmada, ANAP'ın 1991 seçimlerinde uyguladığı seçim stratejisinde bu varsayımın tam karşılığını bulmadığı görülmüştür. Çalışma kapsamında sorulan, "Siyasal liderlerin imajlarında hangi siyasal kültür nitelikleri bulunmaktadır?" sorusu Mesut Yılmaz'ın imajının Türkiye'nin kültürel özelliklerini yansıtmadığı şeklinde yanıt bulmuştur. Siyasal liderin imajı, ANAP'ın seçmenleri ikna etmesini sağlayacak kültürel niteliklere sahip değildir. Bu duruma kanıt olarak 1987 seçimlerine oranla 1991 seçimlerinde ANAP'ın oy oranın önemli düzeyde azalması gösterilebilir. Siyasal mesajların ikna aracı olarak sunulması konusunda çalışmanın kapsamında sorulan "Siyasal kültürün hangi bileșenleri siyasal iletişim sürecinde ikna unsuru olarak kullanılmıştır?" sorusu ANAP siyasal iletişim uygulamaları çerçevesinde yanıtsız kalmıştır. 
Çalışmanın alt amaç sorularından biri olan "Basın ilanlarında ve siyasal reklamlarda yer alan siyasal kültür kodları nelerdir?" sorusu bağlamında incelenen 9 gazete ilanında ANAP'ın kullandığı kültürel nitelikler oldukça kısıtlıdır. Seçim kampanyasında verilen siyasal mesajların kültürel derinliği yoktur. Siyasal iletişim uygulamalarının çeşitli aşamalarının doğrudan siyasal kültür temelinden yükseldiğini söylemek güçtür. Yalnızca ANAP'ın dünyaya açılma vizyonu çerçevesinde, kültürel değerlerin yozlaşmasına izin verilmeyeceği konusunda muhafazakar seçmene güven verilmektedir. ANAP'ın televizyon reklamlarında Yılmaz öne çıkarılmış ancak Yılmaz'ın imajı kültürel kodlarla desteklenmemiștir. Rakiplere karşı sert bir dil benimseyen reklamlar doğrudan muhalefeti ve 1980 öncesi kaotik yapıyı eleştirmektedir.

"Siyasal kültürün siyasal iletişim alanına yansımaları nasıl olmaktadır?" sorusuna karşılık; Günümüzdeki AK Parti'nin prototipi olarak ANAP’ı göstermek mümkündür. ANAP diğer siyasal partilere örnek teşkil edebilecek, özgün nitelikleri olan ve Turgut Özal döneminde siyasal kültüre hakim kişilerce yönetilmiş ve Türk halkına seslenmeyi başarmıştır. Seguela Fransız kültür temeline dayalı olarak çalışmış, Fransız kültürünün özelliklerini ve siyasal kültürünün niteliklerinin Türkiye ile uyum sağlayıp sağlamayacağını yeterince düşünmeden siyasal iletişim kampanyasını gerçekleştirmiştir. Netice itibariyle kültürel kodların ANAP'ın siyasal iletişim uygulamalarında kullanıldığını ve siyasal kültür unsurlarının ANAP'ın seçim çalışmalarını yönlendirdiğini söylemek güçtür.

İnceleme sonucunda elde edilen bulgular ışığında çalışmanın alt amaç sorularından biri olan "Türkiye'de nasıl bir siyasal kültür atmosferi hakimdir?" sorusuna şu şekilde cevap vermek mümkündür: 1990’lı yılların başında ekonomide siyasal kültürün ana unsuru özelleştirme ve kalkınma olmuştur. Sağlık alanında tüm vatandaşlara sosyal güvence sağlanması vaadi, siyasetin kronik sorunu sağlık sektöründeki problemi çözme amacı taşımaktadır. Konjonktürel açıdan yolsuzluk ve rüşvet suçlamaları Türkiye'de siyaset kurumuna ve siyasetçilere duyulan güvensizliği perçinlemesi anlamında ANAP'ın seçim kampanyasındaki en büyük siyasal kültür zafiyetidir.

Seguela'nın Fransa'da yaptığı siyasal iletişim çalışmalarında olduğu gibi Türkiye'de de lider odaklı bir kampanya hazırlamıştır. Tüm seçim stratejisini Mesut Yılmaz'ın üzerine kurmuştur ve liderin ismi ve görüntüsü siyasal partinin mevcudiyetinin önünde ve üstünde konumlandırılmıştır. Bir genel seçim kampanyasından öte Mesut Yılmaz'ın imaj çalışmasını andıran bu kampanyada henüz toplumun çok fazla tanımadığı bir lider olarak Mesut Yılmaz için lider tasarımı yapılmıștır. Kampanyanın en zayıf noktası ANAP'ın kurucu genel başkanı ve eski başbakan olan aynı zamanda o dönemde cumhurbaşkanlığı görevini yürüten Turgut Özal'a hiçbir atıf ya da gönderme yapılmamasıdır.

1980 darbesinden sonra 1983'te başlayan Turgut Özal döneminin ardından Yıldırım Akbulut'tan ANAP koltuğunu devralan Yılmaz ve reklamcısı Seguela toplumu doğru şekilde okuyamamıştır. Bu noktada ANAP'ın, o dönemki toplumsal kültürü baz alarak toplumun büyük kesimini oluşturan mütedeyyin seçmenin kültürel kodlarına paralel bir siyasal iletişim stratejisi geliştirmesi kendisine fayda sağlayabilirdi. ANAP ve Yılmaz kültürel kodları seçmeni ikna edecek birer araç haline getirmeyi başaramamıştır. Dönemin siyasal kültüründeki baskın karakter olan liberal ekonomi ve özelleștirme konusu siyasal iletişim çalışmalarının içeriğinde yer almıştır. 
Vatandaşların en önemli sorunu sağlık sektöründeki eksikliklerdir ve bu dönemde ANAP'ın siyasal iletişim çalışmalarında sağlık alanıyla ilgili hizmetler ve projeler yer almıştır. Yılmaz'ın imajına Türkiye'nin kültürel nitelikleriyle ilgili bir unsur eklemlenmemiştir. Sonuç olarak dönemin toplumsal sorunları, siyasal kültürün baş aktörleri olarak siyasal iletişim uygulamalarında topluma verilen mesajların içeriğinde kendilerine yer bulmuşlardır. Türkiye'de toplum homojen bir siyasal kültür yapısına sahip değildir. Devlet seçkinleri ve elitist kitle ile toplumun orta ve alt kesimi arasında çok büyük kültürel farklılıklar mevcuttur. Bu bağlamda ANAP'ın tabanını oluşturan muhafazakar seçmenin kültürel özelliklerini yansıtan bir seçim kampanyası ortaya konamamıştır. Yapılan tüm incelemeler sonucunda, ANAP'ın siyasal iletişim uygulamalarında kültürel kodlardan yararlanma gayreti içinde olmasına karşın stratejik açıdan toplumun büyük çoğunluğuna hitap eden siyasal mesajlar kültürel unsurlarla desteklememiştir.

Siyasal kültürü çok iyi bilen ve bunu içselleştirmeyi başaran siyasal liderlerin siyasal iletişim sürecinde başarı şansı yüksektir. Toplumla aynı frekansı tutturan ve iletişim stratejisini bu bağlamda yürüten siyasal liderler halkın taleplerini bilir ve buna göre eyleme geçer. Halkın alışa geldiği siyasal kültür ögelerini kullanan lider seçmen kitlesiyle etkili iletişim kurma şansı yakalamaktadır.

Ön kabullerle ele alınan gerçekler işe yarar siyasal iletişim yöntemlerinin geliştirilmesine ket vurmaktadır. Siyasal kültürün omurgasını oluşturan toplumsal hassasiyetleri öne alarak yapılacak siyasal iletişim çalışmaları seçmen tarafinda prim yapabilmektedir. Küreselleşen dünyada dogmaları terk eden siyasal partiler ve liderler öne çıkmakta, lider olmakta ve seçim kazanmaktadırlar. Yaratıcı ve özgün siyasal iletişim çalışmalarıyla siyasal kültürü temel alarak ortaya konan çalışmalar seçmenlerce takdir görmektedir. Küresel düşünüp, yerel hareket eden, bölgesel folkloru, kabulleri, eğilimleri ve siyasal kültürü rehber edinen siyasal iletişim çalışmaları siyasal partileri ve siyasal liderleri başarıya ulaştırmaktadır.

\section{Kaynakça}

Anık, C. (2000). Siyasal İkna. Ankara: Vadi Yayınları.

Aristoteles. (2007). Politika (E. Uysal Çev.). İstanbul: Dergah Yayınları.

Aziz, A. (2007). Siyasal İletişim. Ankara: Nobel Yayınları.

Balandier, G. (2010). Siyasal Antropoloji (D. Çetinkasap Çev.). İstanbul: Türkiye İş Bankası Kültür Yayınları.

Bostancı, N. (1998). Siyaset, Medya ve Ötesi. İstanbul: Vadi Yayınları.

Çankaya, E. (2008). İktidar Bu Kapağın Altındadır Gösteri Demokrasisinde Siyasal Reklamcılık. İstanbul: Boyut Kitapları.

Devran, Y. (2004). Siyasal Kampanya Yönetimi. (2. bs.). İstanbul: Odak İletişim.

Durdu, Z. (2013). Türkiye'de Siyasal Kültürü Anlamak. Ankara: Kadim Yayınları.

Freud, S. (1996). Kitle Psikolojisi. (K. Şipal, Çev.). İstanbul: Cem Yayınevi.

Jasper, J. M. (2010). Kültür, Bilinç, Siyaset. (E. D. Ela, Çev.). T. Janoski, R. Alford, A. Hicks, M. A. Schwartz (Eds.). Siyaset Sosyolojisi. Ankara: Phonenix Yayınları.

Kalender, A. (2005). Siyasal İletişim Seçmenler ve İkna Stratejileri.(2. bs.). Konya: Çizgi Kitapevi Yayınları. 
Kapani, M. (2013). Politika Bilimine Giriş. (33. bs.). Ankara: Bilgi Yayınevi.

Machiavelli. (2012). Hükümdar. (S. Bağdatlı, Çev.). İstanbul: Der'in Yayınları.

McNair, B. (2003). An Introduction to Political Communication. (3. ed.). New York: Routledge.

Oktay, M. (2002). Politikada Halkla İlişskiler. İstanbul: Der'in Yayınları.

Ong, W. J. (2010). Sözlü ve Yazılı Kültür. (S. Postacıoğlu Banon, Çev.). İstanbul: Metis Yayınları.

Ozankaya, Ö. (t.y.). Prof. Dr. Inan Özer'in Siyasal Kültür, Demokrasi ve Demokratik Değerler Adlı Makalesinin Değerlendirilmesi. Erişim: 29 Temmuz 2013, Ă̆ Sitesi: http://www.angelfire.com/oz/sosyo/siyasalkultur.htm

Özbudun, E., Kalaycıŏlu, E. ve Köker, L. (1995). Türkiye'de Demokratik Siyasal Kültür. Ankara: Türk Demokrasi Vakfı.

Özbudun. E. ve Hale, W. (2010). Türkiye'de İslamcılık, Demokrasi ve Liberalizm AKP Olayı, (E. Özbudun, K. Göksel, Çev.). İstanbul: Doğan Kitap.

Özkan, A. (2007). Siyasal İletişim Stratejileri. İstanbul: Tasam Yayınları.

Özkan, N. (2014). Türkiye'den ve Dünyadan Örneklerle Seçim Kazandıran Kampanyalar. (4. bs.). İstanbul: Mediacat.

Platon. (2012). Devlet. (S. Eyüboğlu ve M. A. Cimcoz, Çev.). (22. bs.). İstanbul: Türkiye İş Bankası Kültür Yayınları.

Seguela, J. (1997). Eğlenceli Şeydir Şu Reklamcılık. (N. Önol, Çev.). İstanbul: Milliyet Yayınları.

Smith, P. (2005). Kültürel Kuram. (S. Güzelsarı ve İ. Gündoğdu, Çev.). İstanbul: Babil Yayınları.

Siyasi Partiler Kanunu 3. Madde. (1983). T. C. Resmi Gazete, 2820, 24 Nisan 1983.

Soydaş, A. U. (2010). Kültürlerarası İletişim Farklı Kültürel Ortamlarda Çalışma ve İletişim. İstanbul: Parşömen Yayıncılık.

Tekeli, İ. (t.y.). Türkiye'deki Siyasal Kültürün Demokratikleşmesini Sorgulamak, ODTÜ, Hocam Bu Ay Yine Buluşuyoruz Konuşmaları. Erişim: 3 Eylül 2013, Ağ Sitesi: www.oed.org.tr/oed/images//u3toplantisiilhantekelikonusmasi.dod

Tokgöz, 0. (2010). Seçimler, Siyasal Reklamlar ve Siyasal İletişim. Ankara: İmge Kitapevi.

Topuz, H. (1991). Siyasal Reklamcılık Dünyadan ve Türkiye'den Örneklerle. İstanbul: Cem Yayınevi.

Turan, İ. (1976). Siyasal Sistem ve Siyasal Davranış. İstanbul: Der Yayınları.

Turan, İ. (2009). Türkiye'de Siyasal Kültürün Oluşumu. E. Kalaycıŏ̆lu ve A. Y. Sarıbay (Der). Türkiye'de Politik Değişim ve Modernleşme (s. 517-555). (4. bs.). Bursa: Dora Yayınları.

Uztuğ, F. (2007). Siyasal İletişim Yönetimi. (3. bs.). İstanbul: Mediacat.

Uztuğ, F. (1999). Siyasal Marka: Seçim Kampanyaları ve Aday Imajı. Ankara: Mediacat Yayınları. 
Vergin, N. (2003). Siyasetin Sosyolojisi. İstanbul: Bağlam Yayınları.

Yavaşgel, E. (2004). Siyasal İletişim Kavramlar ve Ardındakiler. Ankara: Ebabil Yayıncılık. 